\title{
Conceptualising Research Methodology for Doctoral Researchers in Open Education (with penguins)
}

\author{
Robert Farrow, \\ The Open University, United Kingdom
}

Bryan Mathers, Visual Thinkery, United Kingdom

\begin{abstract}
This article provides a reflective account of the process of creating a series of visualisations for doctoral researchers. These were created to accompany a handbook about research methods which is aimed at less experienced researchers working in the field of open education. The Handbook was created for members of the Global OER Graduate Network, which supports doctoral research in open education worldwide. The goal of the visualisations were to make complex methodological issues more salient for less experienced researchers, and to support doctoral candidates who might feel overwhelmed or unsupported. Images are openly licensed to promote sharing and reuse.
\end{abstract}

Keywords: Doctoral Research; Methodology; Visualization; Open Education; Research Paradigms 


\section{Background}

The Global OER Graduate Network (GO-GN) is an international network of doctoral candidates, postdoctoral researchers, academics, and associated members. GO-GN brings together those whose research projects include a focus on open education (i.e. open educational resources; open educational practices; MOOCs). There are currently more than 100 members, including more than 40 who have received their doctorate while members of the network. The purpose of GO-GN is to provide support to researchers working in the field of open education, many of whom do not yet benefit from expert supervision in this emerging area, particularly in the Global South. These doctoral researchers are at the core of the network; around them, over two hundred experts, supervisors, mentors and interested parties connect to form a community of practice.

The aims of the GO-GN are:

- to raise the profile of research into open education,

- to offer support for those conducting $\mathrm{PhD}$ research in this area, and

- to develop openness as a process of research.

GO-GN started in 2013 as an initiative from Fred Mulder, UNESCO Chair in OER at the Dutch Open Universiteit, in collaboration with Rory McGreal, UNESCO / COL Chair in OER at Athabasca University (Canada). GO-GN is supported by funding from the William and Flora Hewlett Foundation and administered by a small team in the Institute of Educational Technology at The Open University (UK). GO-GN is currently in its third phase of funding and the growth of the network reflects increasing interest in open education research in recent years.

The GO-GN strives to promote equity, diversity and inclusion in scholarship. As an aspect of openness in science and research, many who identify with the open movement do so to make education more accessible through reduced cost of learning materials; include more diverse voices; and thus advance more inclusive curricula. These values inform open practice and are evident in the research carried out by our members.

Another motif used to convey this is the inverted earth which displays a global map with the southern pole as the top of the map, challenging received notions of academic identity and nodding to the contingent nature of Western intellectual traditions.

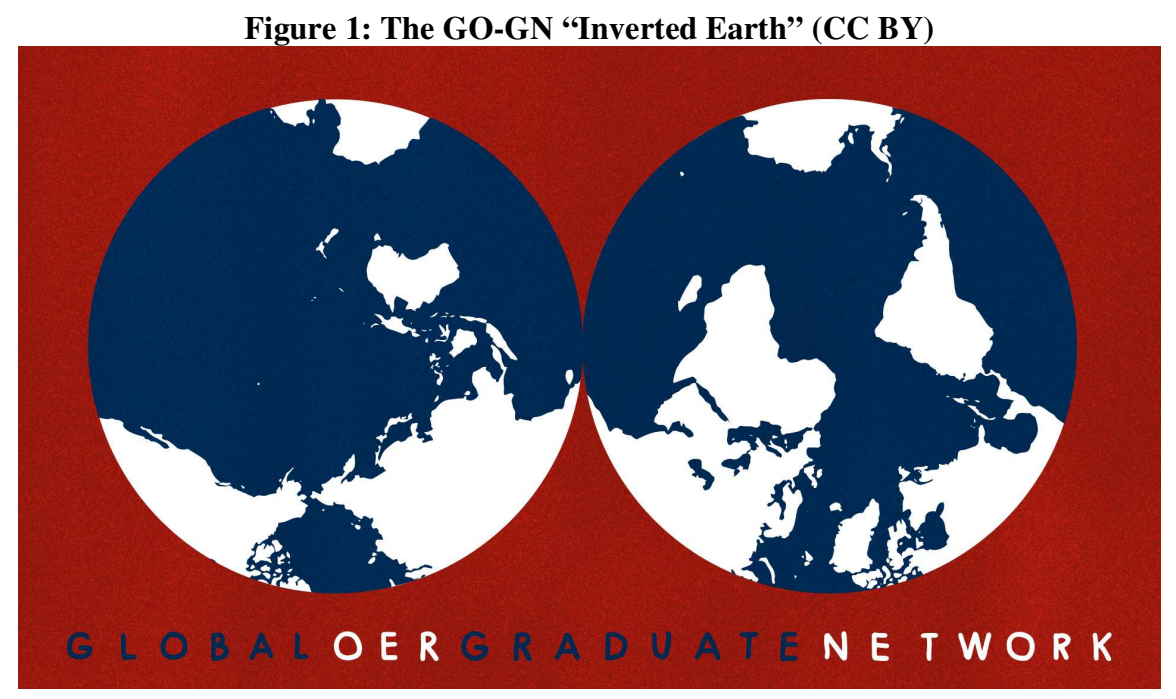

International Journal of Management and Applied Research, 2020, Vol. 7, No. 3 
One of the key activities of GO-GN is an annual international seminar which is usually timed to coincide with the Open Education Global conference (Chtena, 2018; de los Arcos, 2017, 2018; Vladmirschi, 2018; Weller, 2019). GO-GN pays expenses for both the seminar and the conference. This allows for an intensive support process for research and networking which feedback suggests is highly valued by members.

\section{Goals and Visual Style of the Handbook}

A guide to research methods was a common request from GO-GN members. Methodology can be one of the most challenging aspects for doctoral researchers, and since open education is an emergent field additional guidance is appreciated. The Handbook is structured into two parts. The first contains a description of the language, philosophical foundations and concepts of research method with a focus on open education. The second comprises insights about specific methods which have been used by members in their own research.

One of the key aspirations of the Handbook was to provide a complement to existing guidance on research methods, which is comprehensive but not always accessible. Depending on the intellectual history of the researcher, they may be engaging with certain concepts for the first time as they explore a range of research methods and try to understand the philosophical and practical difference between them. This is reflective of how little time tends to be devoted to understanding research methods in higher education, where the emphasis is often on practical use rather than philosophical understanding. This is compounded by the feeling many doctoral learners have that they should (but don't) fully understand the range of methods and methodology.

GO-GN had an existing visual style which was developed for the current phase of the project. This aesthetic was the result of a collaborative visual process, which allowed the participants (the GO-GN team) to collectively explore different avenues to see which resonated. The process was conducted over video conference (in this case, Zoom) with Bryan Mathers as facilitator and "visual scribe". A document camera allows everyone to see a visual landscape of thoughts as they are spoken and captured. The advantage of this method is that the team ends up owning the aesthetic, because the chosen ideas emanated from their own dialogue and are recognisable to them. Figure 2 summarises what was collectively produced through this process.

Figure 2: The GO-GN “Team Conversation” (Mathers, 2019) (CC-BY)

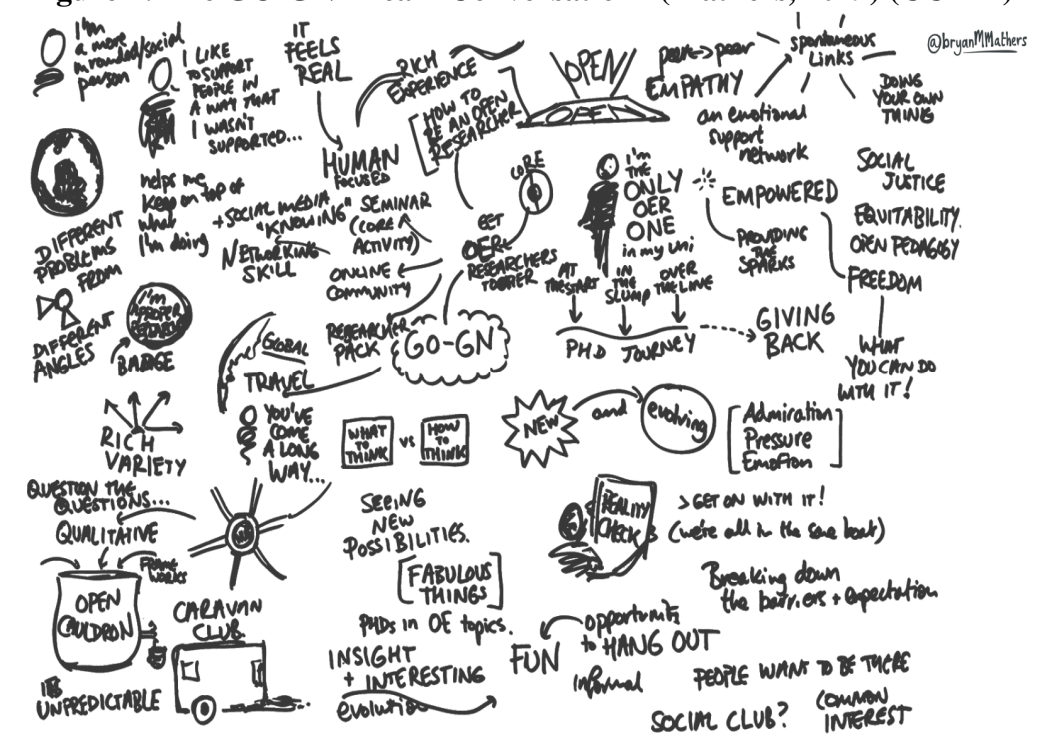

International Journal of Management and Applied Research, 2020, Vol. 7, No. 3 
A similar exercise was also conducted with doctoral candidates and post-doctoral researchers from within the network. Given the centrality of the international seminar and the global nature of the network, a "golden age of travel" theme was intended to convey these (Figure 3) through travel guides, "tickets" for participating in events, passport stamps and other images evocative of broadening horizons, acting as guides, and sharing new experiences.

Figure 3: GO-GN Visual Style (Mathers, 2019) (CC-BY)
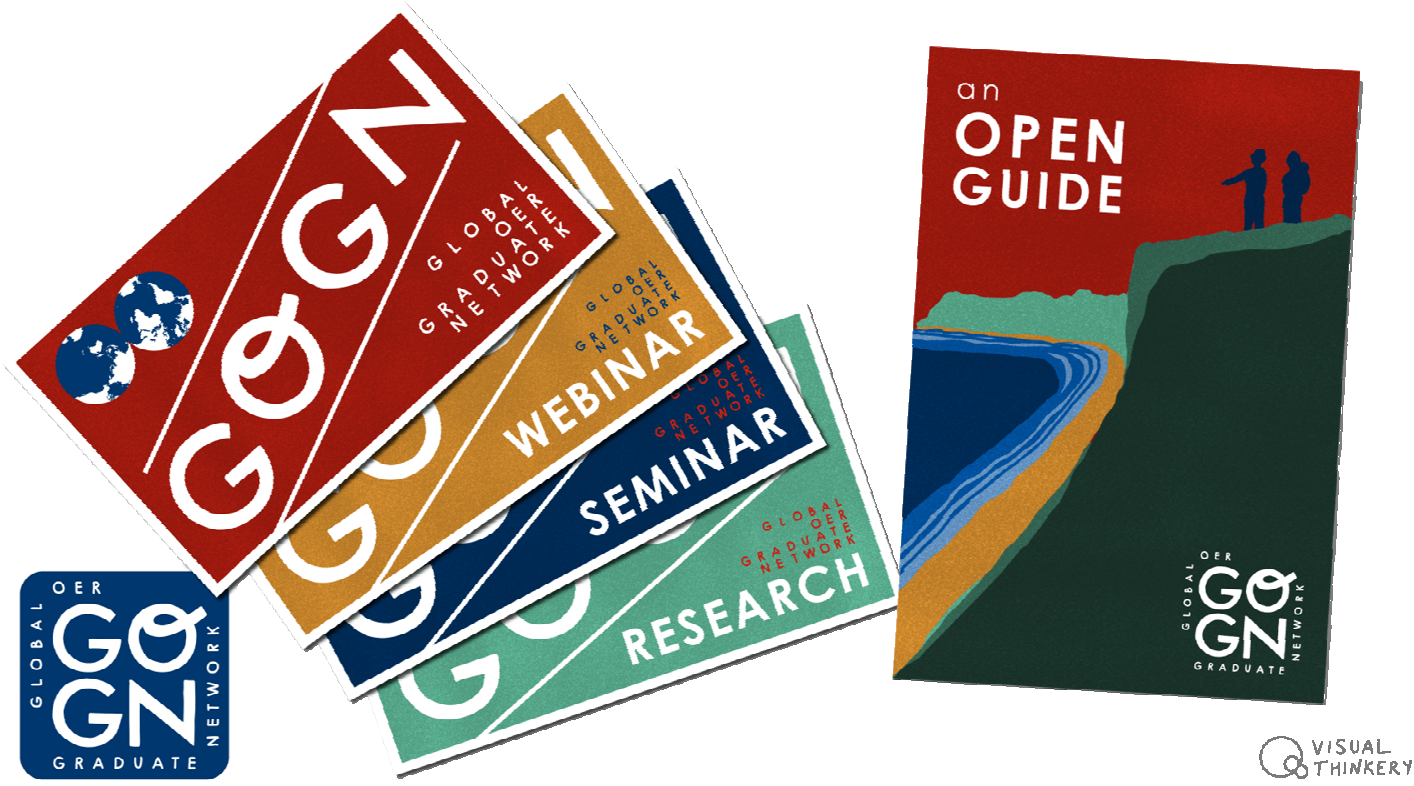

Channeling a bygone age of exploration and personal development in 2019 seems particularly ironic given the disruption to travel that was to come with Covid-19 - many events (including the GO-GN seminar) have become online only events. However, we wanted to retain the motifs of journeys and making new connections evident in our research methods guide. This was intended to reflect two things: the idea of doctoral study as a personal and intellectual exploration; and the newness of open education as a field of study and research.

\section{Penguins}

Figure 4: GO-GN Penguins (Farrow et al., 2020) (CC-BY)
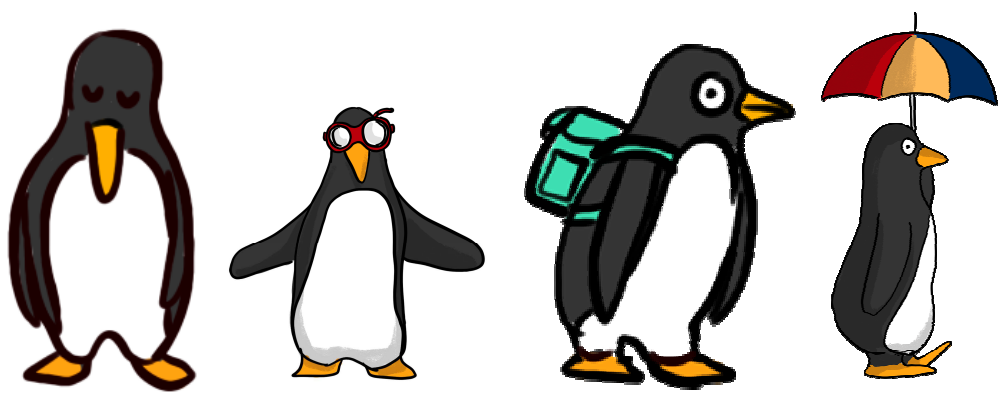

Bryan: Who doesn't love a penguin? Curious, collaborative, and playful: but also vulnerable, exposed, on a yearly pilgrimage through the bitter Antarctic desert, surviving against the odds. It's no wonder it resonated with the GO-GN community. From an artist's perspective, having the golden age of travel

International Journal of Management and Applied Research, 2020, Vol. 7, No. 3 
aesthetic and a mascot already provides the syllables of a rich visual language. But the other element is the visually-barren wasteland of a huge academic document...

The other element of visual style in the handbook developed organically. The original GO-GN visual concept did not include the penguin mascot. When the GO-GN organising team were preparing for a conference and ordering some branded merchandise there were various animals available for adding your logo to. The penguin was chosen on account of its association with the Southern hemisphere as promotion of research and scholarship from the Global South is one of the stated aims of the network. A penguin that travels is kind of contradictory given that they are found in particular kinds of environments, but that sense of dislocation and having to learn how to function in a new environment is common in doctoral scholarship.

The popularity of the (genderless and nameless) mascot encouraged us to portray the penguins' journey as a visual analogue to the researchers' navigation through choices about research methods. The penguins display a range of emotions, offering the possibility of an emotional or empathic connection which contrasts with the typically cerebral tone of most research methodology guidance. Throughout the Handbook, attempts are made to explain, summarise and link to (rather than replace) existing guidance.

The penguins proved so popular among members and the wider community that we had many requests for plush penguin mascots! Many GO-GN members now have their own penguin and share photographs of themselves with their penguin at their own institution or when they travel or attend a conference. (An Instagram account is dedicated to collecting these photos at https://www.instagram.com/go_gn_penguin/.) Quite organically, the GO-GN community identified with the penguin and this was used to develop a visual journey through the landscape of research methods.

\section{The Research Journey}

Figure 5: The "Iceberg" Model of Research Method and Philosophical Foundations (Farrow et al., 2020:9) (CC-BY)

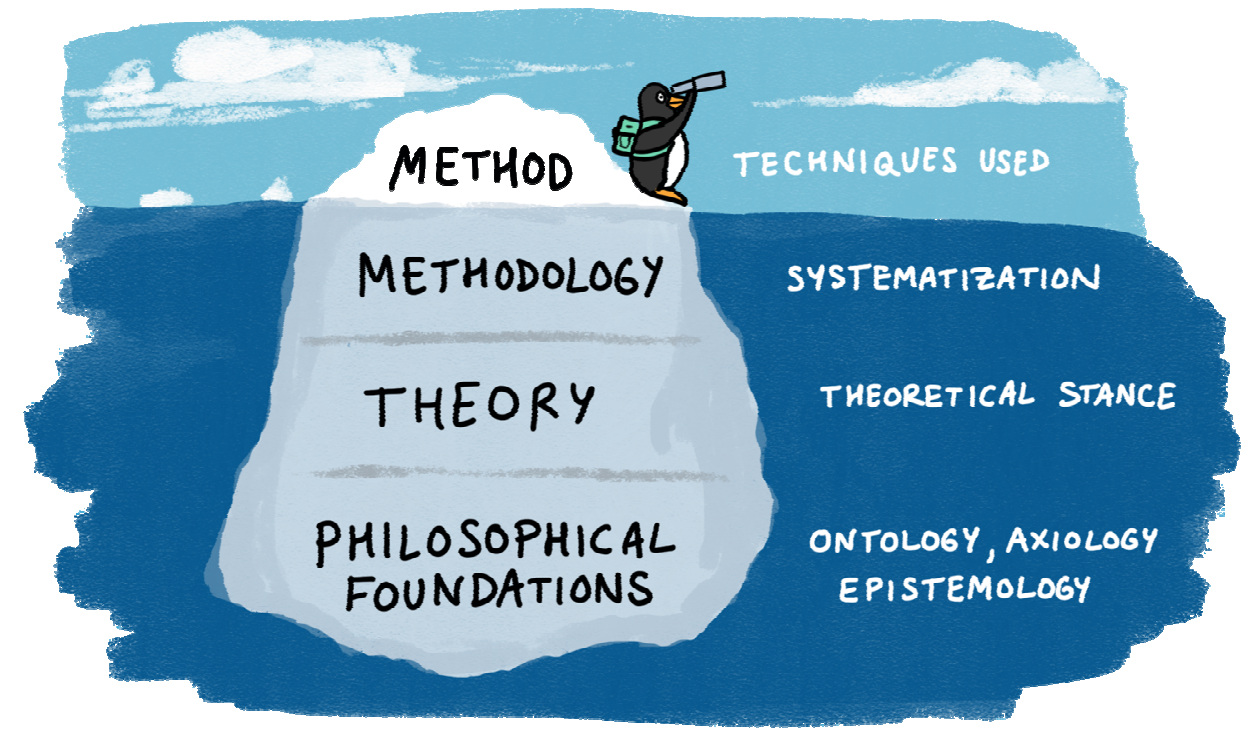

International Journal of Management and Applied Research, 2020, Vol. 7, No. 3 
The starting point chosen for explaining methodologies was to allude to the philosophical differences that distinguish paradigmatic approaches. Some well establish research frameworks were used for framing (Crotty, 1998; Guba and Lincoln, 1994; Heron and Reason, 1997). These typically discuss the philosophical foundations of research and knowledge creation with reference to philosophical terms that can be intimidating: ontology (the science of being); epistemology (the science of knowing) and axiology (the study of values and value judgements). For those without a background in philosophy these can be challenging concepts. In the Handbook they are accompanied by passport style stamps (Figure 6) to indicate that they are a necessary part of the journey.

Figure 6: The GO-GN "Travel Stamps" for Ontology, Epistemology and Axiology (Farrow et al., 2020:9-11) (CC-BY)
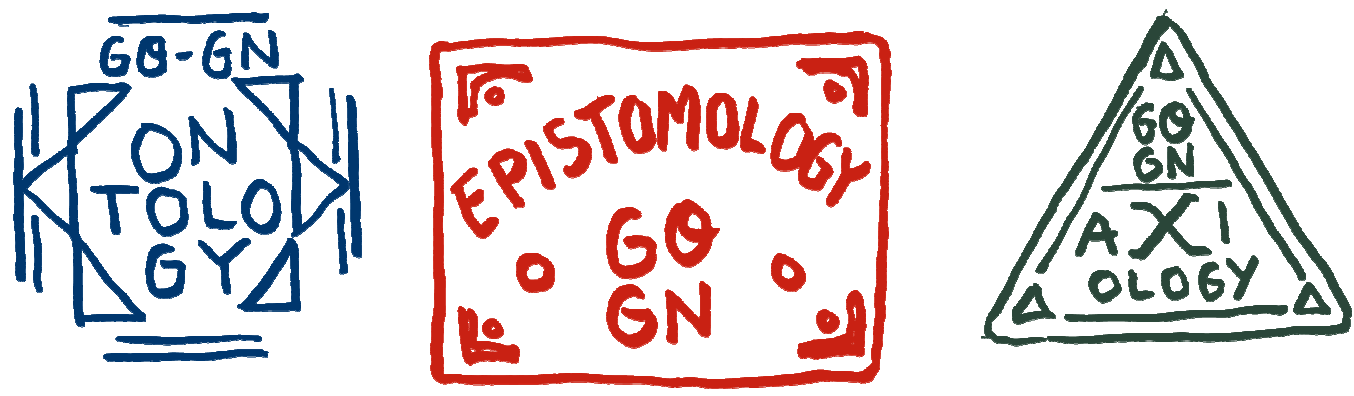

The idea of passport stamps came directly from group dialogue in the Visual Thinkery session.

Bryan: Before the reader has engaged with the text and the ideas presented, the images have already "spoken". Maybe they say "like me, you are on a journey" or "you are not alone" or even "well, this is weird". It depends on the reader what meaning they may take from it. Each penguin stands in solidarity with the reader - "we're also trying to make sense of these words, too...". Cognitive ease allows the reader to feel that they are already making progress on their learning journey - and helps to keep them engaged. The use of humour and understatement is intended to be disarming. Visually, it can simply be the bemused expression on the face of the penguin - or the fact that anyone would have a passport that contained an ontology stamp... By creating these as passport stamps, we are giving them importance. We are saying they are different from each other, and worth knowing all about. But we're also creating a visual link between three abstract scientific-sounding words and the real world. Not only that, but these images have momentum. They say "you will have made good progress when you have experienced and understood what this means".

A further level of complexity is added when the theoretical foundations of research are combined with specific research methods. Many existing descriptions - several of which are cited in the handbook - are quite dry and technical. We tried to temper this material with some more light-hearted illustrations.

The challenge here was to find an approach that could successfully convey complexity while offering a supportive analysis of the range of approaches that are used. Figure 7 compacts a lot of information into one graphic. It shows the spectrum of metaphysical and epistemological commitments as a rainbow of options with associated methodologies.

International Journal of Management and Applied Research, 2020, Vol. 7, No. 3 
Figure 7: The Spectrum of Research Approaches and Paradigmatic Research Methods (Farrow et al., 2020:19) (CC-BY)

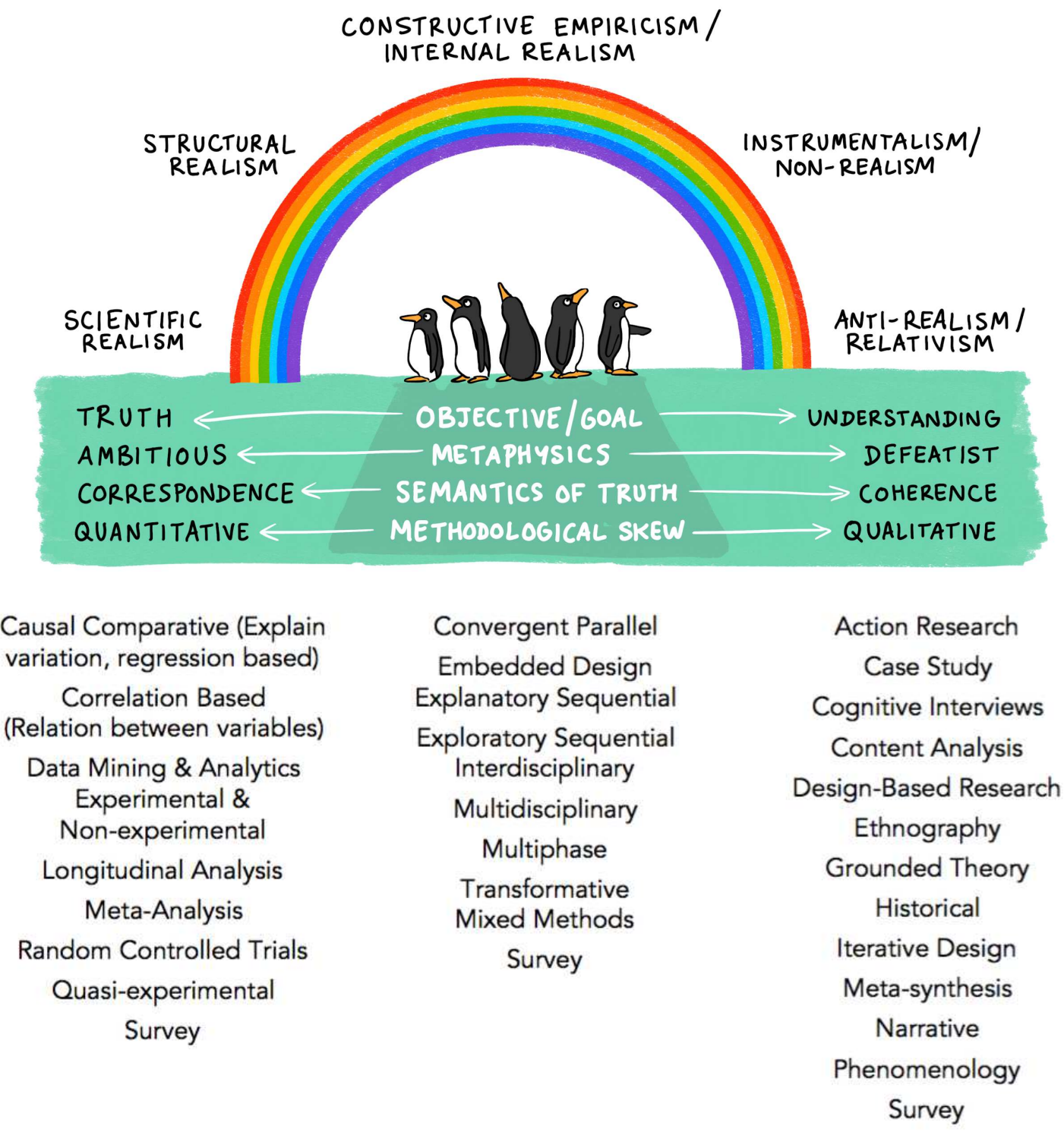

Bryan: Translating this visually from an initial sketch was complex. There is so much information to relay. Firstly I needed to decode it, to understand the mechanics of what it was trying to say... I thought first about a dial - or a knob - that could be turned from Scientific Realism to Anti-Realism. Which then turned into a rainbow, with the added connection of the word "spectrum". The penguins looking up and wondering at the rainbow then seemed obvious, as they became the focal point for the visual idea. A rainbow in itself is a thing of wonder, and so it's an appropriate feeling to inject into this diagram.

In addition to creating our own graphics we also redrew and modified tables created by others where we thought they were especially concise or impressive (with full citations, naturally).

International Journal of Management and Applied Research, 2020, Vol. 7, No. 3 
Figure 8: Research Design Process (based on Open University, 2014) (CC-BY)
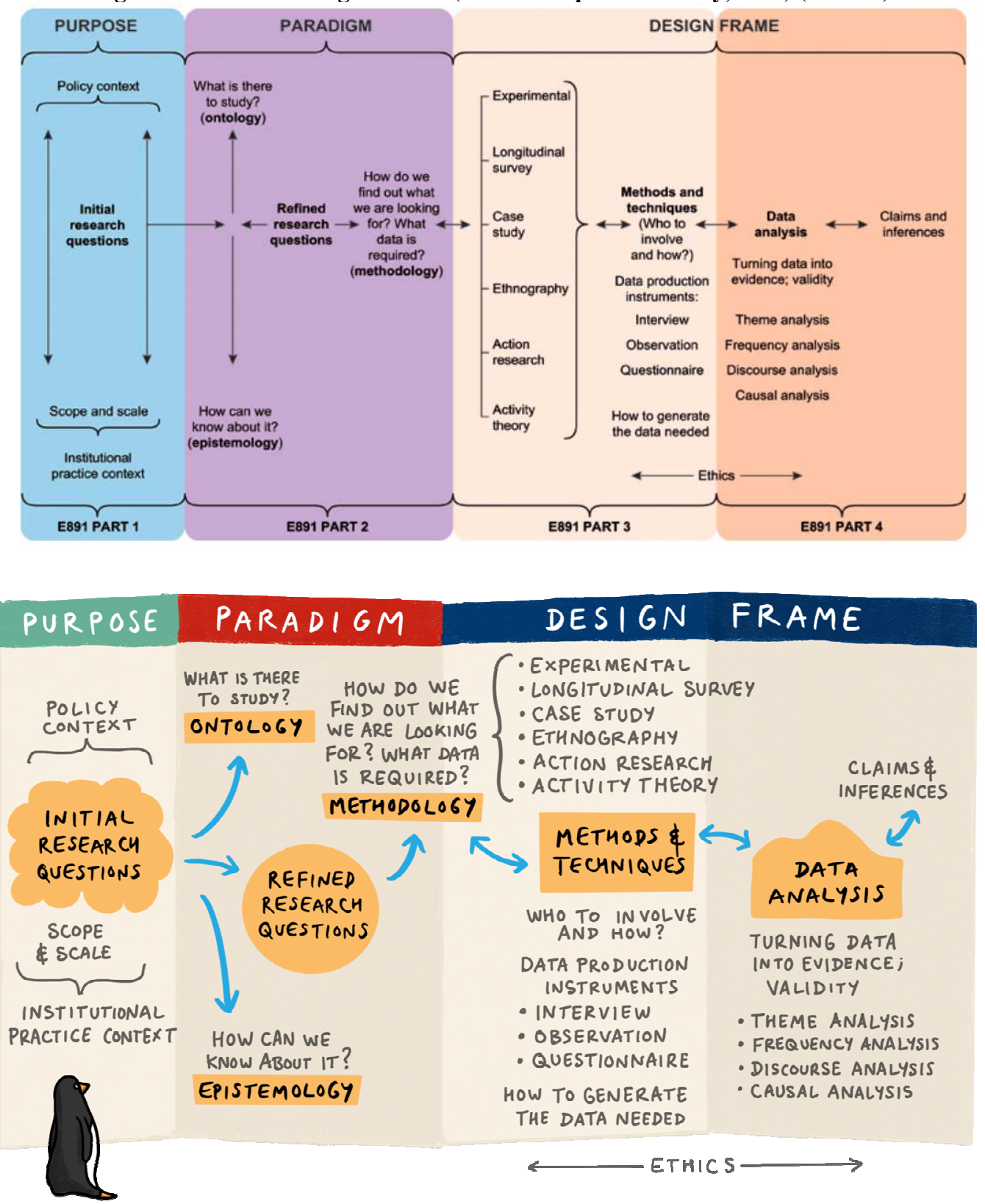

This diagram (inspired by a table from an archived Open University (UK) course entitled E891 Educational Inquiry which is shown above) shows one way to schematise the research design process.

Here, one begins with a research question and a context for the research (comprising policy and practice). This informs the potential scope and scale of the project. The next element is to consider the paradigmatic research approach that will be used, thinking about the ontological and epistemological elements.

Bryan: This illustration probably took the longest to create. The more words that are added, the more the perceived complexity at first glance. The original

International Journal of Management and Applied Research, 2020, Vol. 7, No. 3 
table looked like a map to me, and so by creating a folded paper look, it gives a little bit of depth to the drawing. By highlighting the central path of the diagram and again adding a penguin suddenly the reader has an ally in mapping out its meaning.

Like Figure 8, Figure 9 attempts to guide the reader through the research process. The difference here is that it offers a comparison for different research paradigms. This is actually a redrawing (with some modification) from a recent paper which explains and explores research paradigms in medical education (Brown and Dueñas, 2020). Here the table - which condensed an impressive amount of information - was simplified and given a style consistent with the rest of the Handbook.

Figure 9: Progression through the Research Process (based on Brown and Dueñas, 2020) (CC-BY)

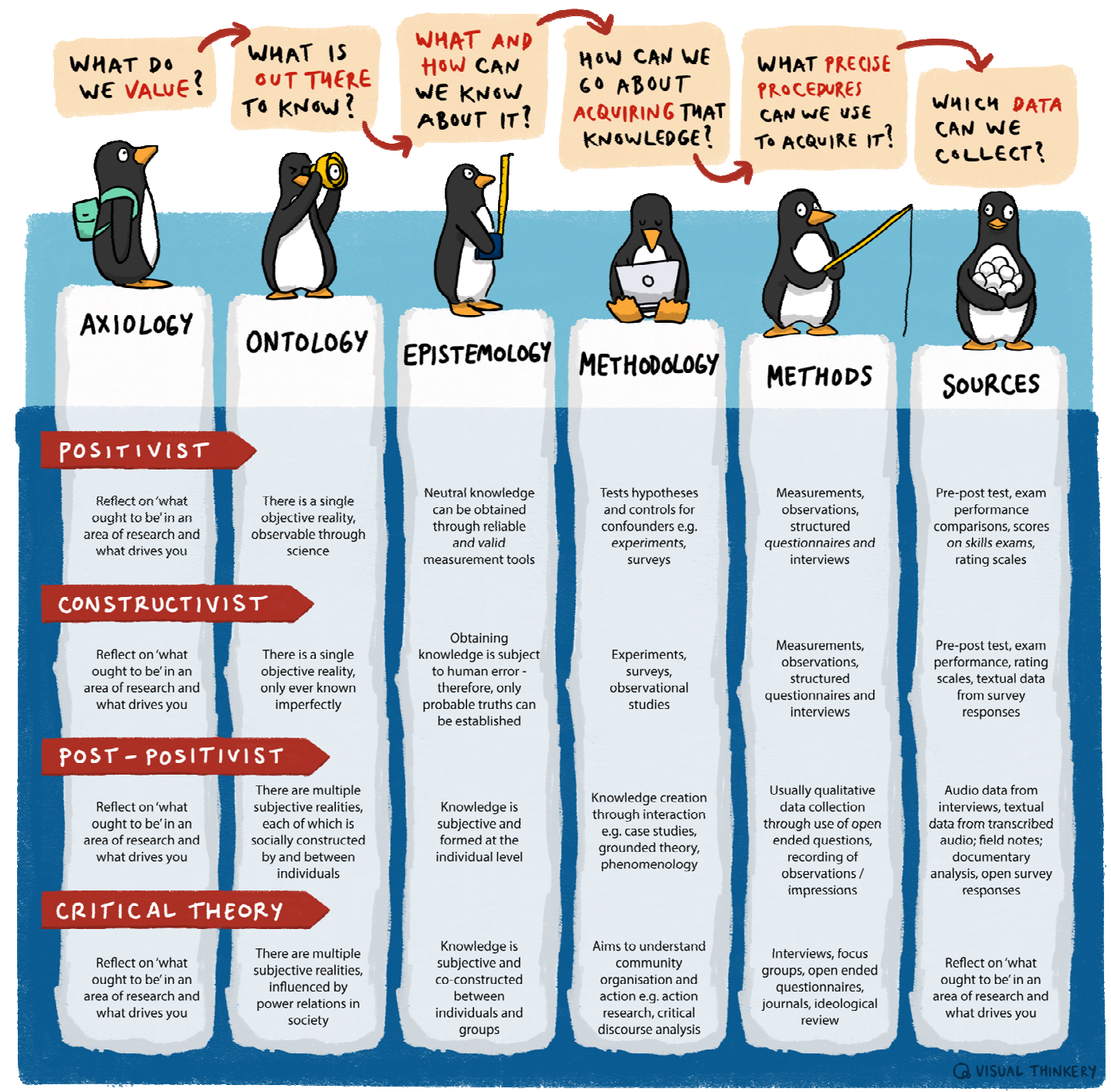

Bryan: There is something so charming about penguins doing playful things you don't expect. For each one, the aim is to build a bridge between the title of the column and the penguin's action. So much of the meaning is communicated via the eye of the penguin - forming a connection between it and the reader.

International Journal of Management and Applied Research, 2020, Vol. 7, No. 3 
This is very common in illustrated children's books - from which I have learned so much.

\section{Concluding Reflections}

Most of these illustrations are from the first half of the Handbook, which is more narrative in style. The latter half of the Handbook comprises brief guides to specific methods, illuminated by insights from GO-GN researchers who have used a specific method in their doctoral research. Though there are fewer visual cues offered here, arguably this is the most valuable part of the handbook in terms of capturing and presenting the authentic experiences of doctoral researchers in open education and their insight into different methods. In some ways, the more practical advice in the latter half of the Handbook is less in need of visual cues because it is less abstract and more narrative. We hope that the imagery presented in the first half of the Handbook helps to support the reader in understanding the insights offered by GO-GN researchers.

The Handbook - and the images themselves - are openly licensed with a Creative Commons CC BY Attribution licence (Creative Commons, n.d.). This means that anyone is free to re-use the images or report in any way as long as they provide attribution back to us. This is a common practice in the open education world which has been shown to massively enhance the reach and use of various works. In this case it means others can build upon what we have produced, share the Handbook freely and take small or larger parts to use in other works. The full collection of images used in the Handbook is available from http://go-gn.net/wpcontent/uploads/2020/06/GO-GN-image-collection.zip.

\section{References}

1. Brown, M.E. and Dueñas, A.N. (2020), “A Medical Science Educator's Guide to Selecting a Research Paradigm: Building a Basis for Better Research", Medical Science Educator, Vol. 30, No. 1, pp. 545-553. https://doi.org/10.1007/s40670-019-00898-9

2. Chtena, N. (2018). Reflecting on \#OEGlobal18 and GO-GN's seminar|GO-GN. Retrieved 10 August 2020, from http://go-gn.net/seminar/reflecting-on-oeglobal18-and-go-gnsseminar/

3. Creative Commons (n.d.). About $\quad \mathrm{CC}$ Licences. https://creativecommons.org/about/cclicenses/

4. Crotty, M. (1998). The Foundations of Social Research: Meaning and Perspective in the Research Process. London: Sage.

5. de los Arcos, B. (2017), Two and a half days in Cape Town|GO-GN. [Online] Available from: http://go-gn.net/seminar/two-and-a-half-days-in-cape-town/ [Accessed on 10 August 2020].

6. de los Arcos, B. (2018), What happened when we put 14 PhD researchers inside an IKEA hotel | GO-GN. [Online] Available from: http://go-gn.net/seminar/what-happened-whenwe-put-14-phd-researchers-inside-an-ikea-hotel/ [Accessed on 10 August 2020].

7. Farrow, R., Iniesto, F., Weller, M. and Pitt., R. (2020), The GO-GN Research Methods Handbook. UK: The Open University. CC-BY 4.0. http://gogn.net/gogn_outputs/research-methods-handbook/

International Journal of Management and Applied Research, 2020, Vol. 7, No. 3 
8. Guba E. and Lincoln, Y. (1994), "Competing paradigms in qualitative research", In Denzin, N. and Lincoln, Y (eds.), Handbook on qualitative research. Thousand Oaks, Ca: Sage, pp. 105-118.

9. Heron, J. and Reason, P. (1997), “A participatory inquiry paradigm”, Qualitative Inquiry, Vol. 3, No. 3, pp. 274-294. https://doi.org/10.1177/107780049700300302

10. Mathers, B. (2019). "GO-GN Project", Visual Thinkery. [Online] Available from: https://visualthinkery.com/project/go-gn/ [Accessed on 10 August 2020].

11. The Open University (2014), "Part 4: The analysis of data", E891 Educational enquiry, Milton Keynes, The Open University.

12. Vladimirschi, V. (2018), The GO-GN Seminar and OE Global Conference 2018: Reflections and Experiences [Online] Available from: https://ds4oervladimirschi.wpcomstaging.com/2018/05/10/the-go-gn-seminar-and-oeglobal-conference-2018-reflections-and-experiences/ [Accessed on 10 August 2020].

13. Weller, M. (2019), The Galway GO-GN experience | GO-GN. [Online] Available from: from http://go-gn.net/seminar/the-galway-go-gn-experience/ [Accessed on 10 August 2020].

International Journal of Management and Applied Research, 2020, Vol. 7, No. 3 